\title{
Uso del Protocolo Reverso en el tratamiento de pacientes con carga diferida: Reporte de Caso.
}

\author{
Use of Reverse Protocol in the treatment of patients afterloading. Case report. \\ Roxana Escudero Loayza ${ }^{l, a}$, Carlos Matta Morales ${ }^{l, a, b, c}$
}

\section{RESUMEN}

La continua reabsorción mandibular tras la pérdida de las piezas dentarias trae consigo una falta de retención de las dentaduras completas, por lo que el uso de implantes dentales se ha convertido en una de las alternativas de tratamiento más utilizadas para mejorar esta situación. Hay que recordar que una adecuada evaluación tanto de la calidad ósea como del soporte muscular son necesarios previo a la realización de una rehabilitación implantosoportada para poder alcanzar el éxito en el tratamiento. En este articulo se presenta un reporte de caso clínico donde se utilizó la técnica de protocolo reverso para la confección de una prótesis hibrida maxilar combinada con prótesis fija mandibular.

\section{Palabras clave: PRÓTESIS HÍBRIDA, OCLUSIÓN, DISEÑO PROTÉSICO.}

\section{SUMMARY}

The continuous process of bone resorption subsequent to the loss of teeth entails a lack of retention of complete dentures; therefore the use of dental implants has become one of the most frequently used treatment alternatives to improve this situation. We must remember that a proper assessment of both bone quality and muscular support is necessary prior to the performance of implant-supported rehabilitation to be able to succeed in treatment. This article presents a case report where we used the technique of reverse protocol for making maxillary hybrid prosthesis in combination with a mandibular fixed prosthesis.

Keywords: HYBRID PROSTHESIS, OCCLUSION, PROSTHETIC DESIGN.

\footnotetext{
Facultad de Estomatología Roberto Beltrán, Universidad Peruana Cayetano Heredia. Lima, Perú.

a Especialista en Rehabilitación Oral y Maxilofacial.

b Magister en Estomatología.

c Profesor.
} 


\section{INTRODUCCIÓN}

La rehabilitación oral de la maxila edentula es aun un reto, especialmente en zonas de atrofia y cuando la carga temprana o inmediata es requerida (1). La investigación clínica en el tratamiento de los maxilares edentulos con restauraciones fijas implanto soportadas han demostrado predictibilidad en resultados a largo plazo (2-4). La maxila edentula es distinta de la mandíbula tanto a nivel macroscópico como microscópico, así la calidad ósea en la porción intraforaminal mandibular es esencialmente diferente del hueso maxilar, que es más trabeculado y por ende menos denso (4). Por ello se podría decir que es más difícil alcanzar niveles elevados de estabilidad en la colocación de implantes (estabilidad primaria) en la maxila. En un hueso menos denso el uso de implantes de diferentes formas, longitud y diámetro nos pueden ayudar a sobrellevar estas limitaciones anatómicas y permitir una estabilidad primaria mayor (1).

Hay que tener en cuenta que la reabsorción ósea especialmente en la zona posterior maxilar, disminuye la posibilidad de colocación de implantes. Por ello, diferentes técnicas que incluyen el uso de implantes inclinados, cortos, implantes pterigoideos, levantamiento del seno maxilar e incluso implantes cigomáticos han sido descritos para la maxila atrófica (1).

Esto dependerá mucho de los exámenes auxiliarles previos, considerando que la técnica del protocolo reverso nos da una aproximación más cercana al resultado final, hemos utilizado esta alternativa para asegurar el resultado disminuyendo las posibilidades de error (5).

El objetivo del presente trabajo fue mostrar que realizando un análisis exhaustivo antes de la colocación de los implantes podemos obtener una mejor predictibilidad en cuanto a los resultados protésicos finales.

\section{Oclusión}

La elección de un esquema oclusal para dentaduras completas implanto-soportadas es controversial. La mayoría de parámetros están dados en base a dentaduras naturales, y no hay estudios clínicos publicados que comparen las diferentes teorías oclusales (6).

El objetivo en todo tratamiento protésico debe incluir el establecimiento de una oclusión funcional (7). La oclusión en dentaduras completas implanto soportadas debe reducir el estrés en los implantes (8). Se debe distribuir las fuerzas a lo largo de todos los implantes; Nikolopoulou F. menciona que la oclusión elegida para dentaduras completas implantosoportadas debe ser una oclusión balanceada asegurándonos de que no existan interferencias en los movimientos mandibulares en posiciones excéntricas (6). Por otra parte una oclusión mutuamente protegida optando por una función en grupo también es una opción viable. No debemos olvidar que la elección del esquema oclusal va a depender también del tipo de arcada antagonista que presente el paciente.

Muchos de los fracasos en implantología pueden ser atribuidos a un inadecuado esquema oclusal, el cual concentra el estrés a nivel óseo llevando a una reabsorción ósea acelerada. Ciertas reglas son recomendadas para establecer un diseño oclusal adecuado dentro de las cuales tenemos (6):

- Las cúspides deben dirigir el estrés a lo largo del cuerpo del implante (considerando que el ángulo de desoclusión que no provocaría mucho estrés en las paredes laterales de los implantes es de $45^{\circ}$ )

- Eliminar el estrés lateral

- Reducir las tablas oclusales

- Reducir la altura de las cúspides

\section{Mantenimiento}

Buena parte del éxito de la terapia con implantes depende del buen planeamiento y habilidad en los procedimientos quirúrgicos y diseño protésico. Sin embargo, la habilidad del paciente para realizar una higiene oral continua y efectiva tiene un impacto sobre el éxito terapéutico a largo plazo (9). Se debe recomendar el uso de cepillos interproximales, hilo dental con características especiales como: una de los extremos debe ser rígido para facilitar el pasaje por debajo de la estructura así como tener en parte de su recorrido una forma esponjosa que permita no solo retirar restos de alimento, si no también placa blanda y hacer un ligero masaje sobre el tejido cubierto para estimular el cambio celular superficial, instrumentos como irrigadores, entre otros. Los controles en pacientes concientizados (que entienden la importancia del cuidado de sus tejidos y su prótesis, es decir placa bacteriana y sensación de incomodidad o sobrecarga) podría realizarse cada 4 meses durante el primer año, y posteriormente, el retiro de la prótesis 
con su respetiva limpieza deberá realizarse después de 12 a 18 meses, si luego de los primeros controles se observara lo contrario el tiempo de control podría reducirse.

\section{Caso clínico}

Paciente de sexo masculino de 64 años de edad en ABEG, acude al Servicio del Postgrado de Rehabilitación Oral de la Facultad de Estomatología de la Universidad Peruana Cayetano Heredia. Al examen clínico presenta prótesis fija en mal estado y atrición moderada en el sector antero inferior (Figura $1 \mathrm{~A}, 1 \mathrm{~B}$ y $1 \mathrm{C})$.
En la radiografía panorámica se observa el maxilar superior con reabsorción ósea severa en el sector anterior Figura 2.

Se procede al retiro de las prótesis fija y se toma una impresión funcional (se combinó silicona por adición de consistencia fluida para conseguir escurrimiento y mediana para que el producto final tenga densidad) para la confección de una placa base y rodete que nos servirá para determinar la dimensión vertical (evaluando el espacio disponible para la confección de la prótesis implanto soportada) así como también el soporte de los tejidos blandos (5) (Figura 3A, 3B y 3C).

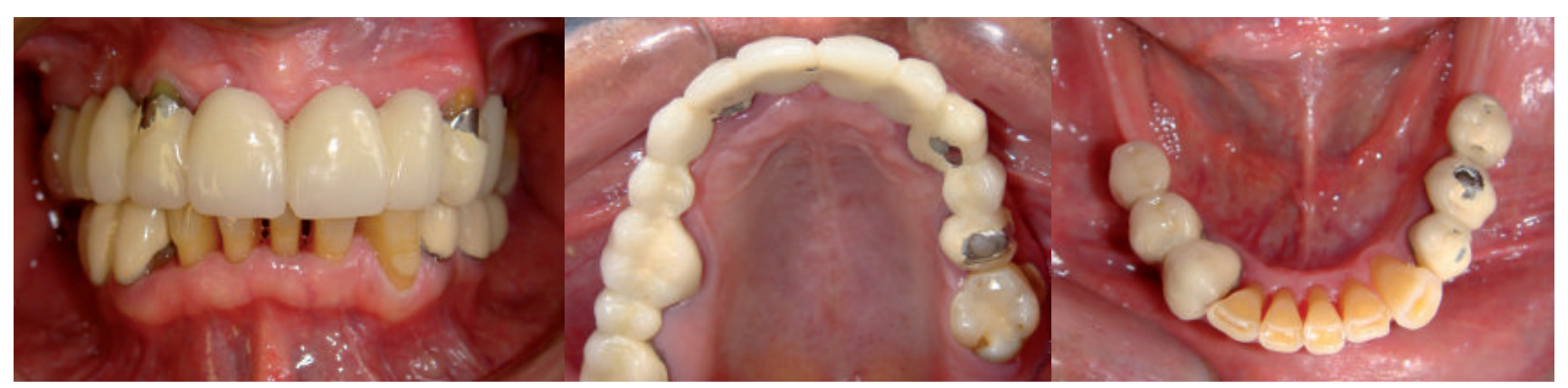

Figura 1. A. Maxima intercuspidación, B. Vista Oclusal Superior y C. Vista Oclusal Inferior

Se duplica el encerado realizado para la confección de una guía tomográfica, en la cual se preparan ductos, los cuales son rellenados con gutapercha en barra, los cuales servirán como marcadores al momento del examen de imágenes, ubicando la probable posición en la cual se colocara el implante respectivo y a su vez con gutapercha rosada (conos de gutapercha empleados en endodoncia) en la zona vestibular para evaluar el contorno (Figuras 4A y 4B).

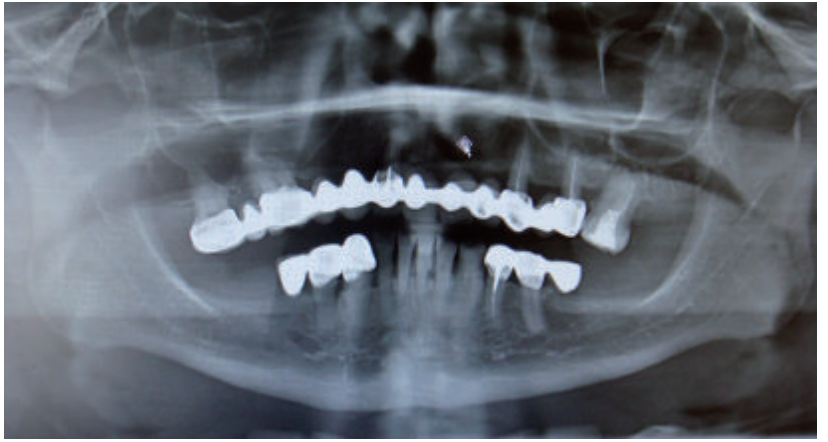

Figura 2. Radiografía panorámica inicial del paciente

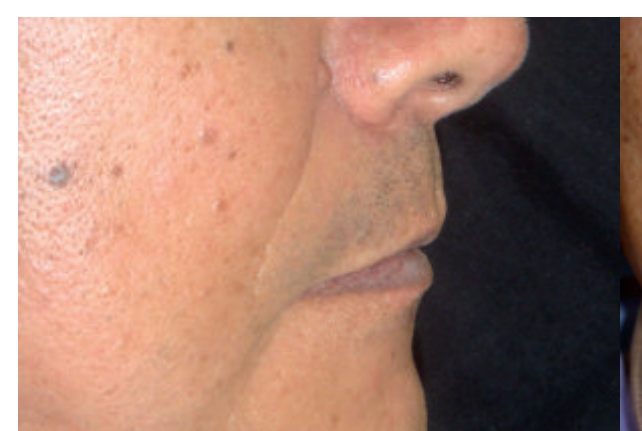

Figura 3. A. Soporte labial

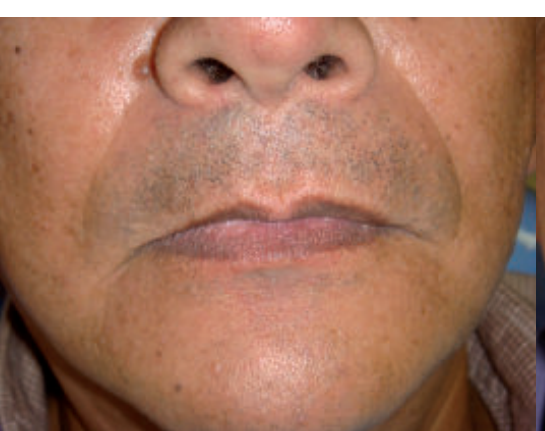

B. Longitud del labio

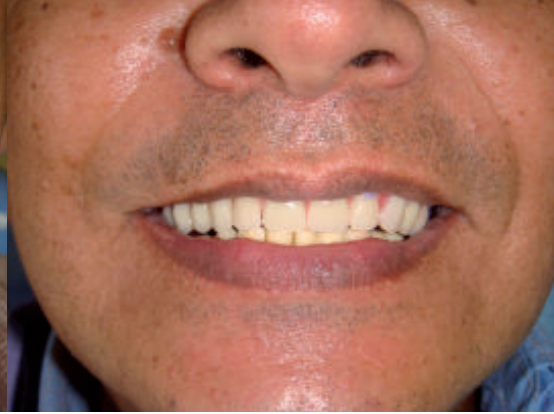

C. Línea de la sonrisa 


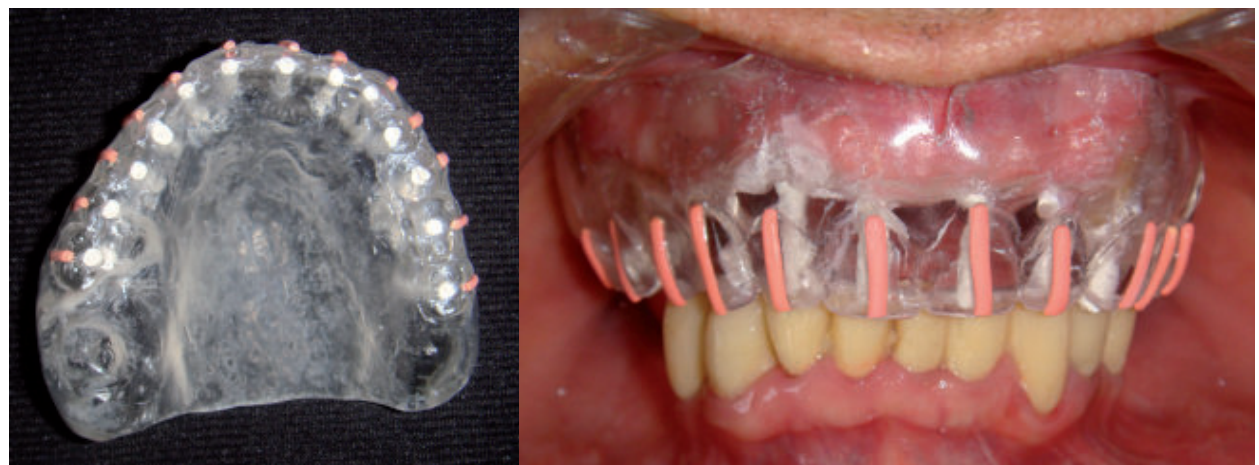

Figura 4. A. Guía multifuncional y B. Guía multifuncional en máxima intercuspidación

Una vez obtenida la imagen tomográfica (Tomografía Computarizada Cone Beam) se procede a realizar las mediciones en las zonas donde se van a colocar los implantes, dependiendo del programa utilizado.

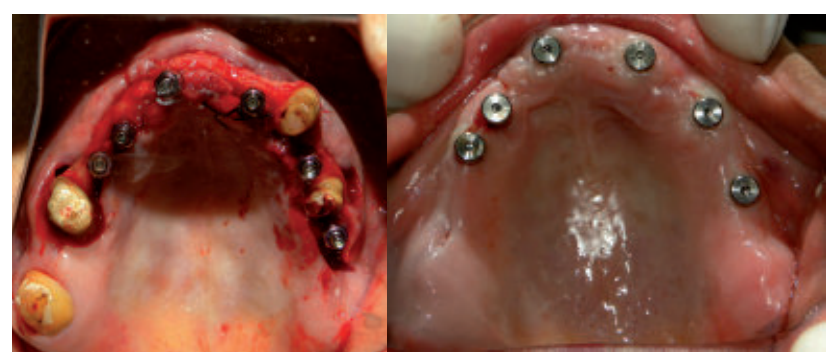

Figura 5A y 5B. Cirugía de implantes.

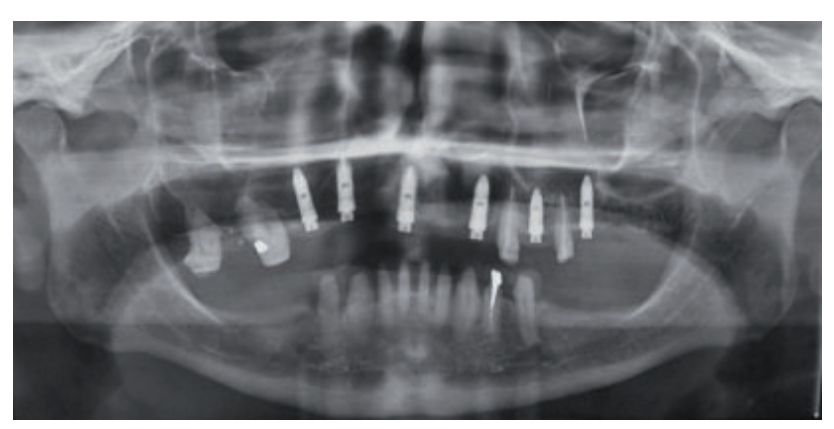

Figura 6. Radiografía panorámica final
Se procede a la cirugía teniendo como referencia la Guía Multifuncional (guía tomográfica confeccionada previamente) que ahora será nuestra guía quirúrgica. (Figuras 5A y 5B).

A los 2 meses se procedió a la exodoncia de las piezas. La cirugía de segunda fase se realizó 6 meses posterior a la colocación de los implantes y se evaluó mediante la radiografía panorámica (Figura 6).

Se seleccionaron los pilares y la profundidad del transmucoso con el probador de pilares, todos los pilares empleados fueron Mini Pilar CM Recto (Neodent) los cuales se ajustaron a $30 \mathrm{~N}$ (según indicaciones del fabricante). Posteriormente se transfirió la ubicación de los pilares para lo cual se ferulizaron los aditamentos de transferencia con barras metálicas unidas con acrílico de combustión completa (alta estabilidad dimensional luego de la polimerización), se verifica que la cubeta individual confeccionada asiente adecuadamente, en caso la ferulización no permita un ingreso adecuado, se procede a desgastar la cubeta. Una vez tomada la impresión se colocan los análogos y alrededor de ellos silicona para simular la encía en el modelo.

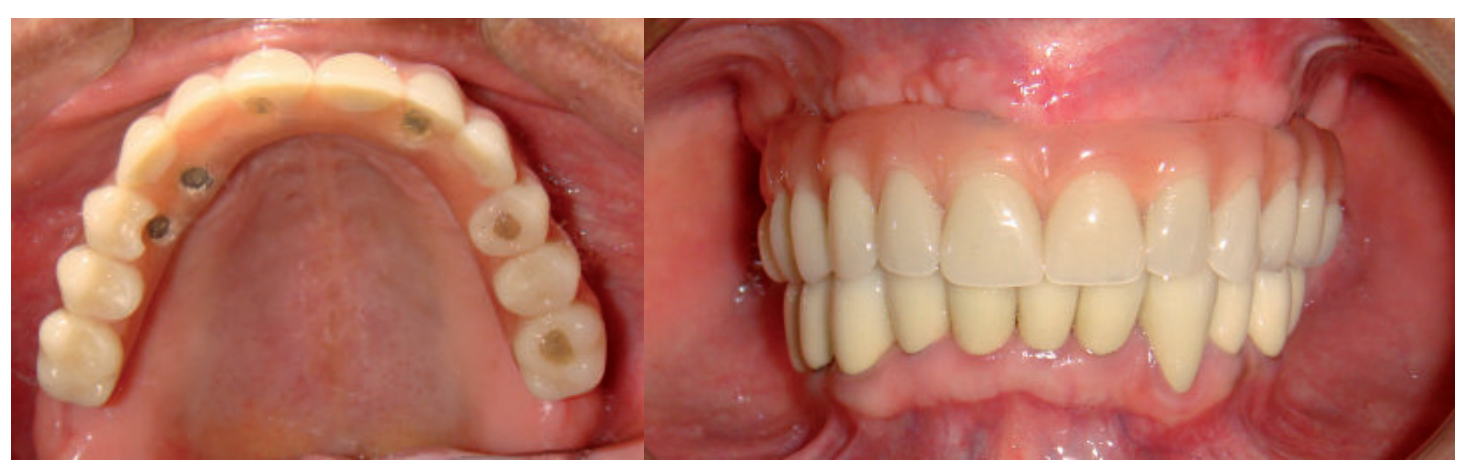

Figura 7A. Vista oclusal y B. Máxima intercuspidación. 
Se realizan las pruebas del rodete y luego el enfilado, se toma una guía con silicona para que el técnico elabore la estructura metálica dentro de los límites de la prótesis. Una vez probado el asentamiento pasivo de la estructura se procede a reubicar las piezas considerando la posición del primer enfilado. Simultáneamente se confeccionaron las coronas del maxilar inferior

Finalmente se realiza el acrilizado de la prótesis, hay que verificar siempre la convexidad de la parte interna en contacto con la mucosa para facilitar la higiene del paciente y evitar el acumulo de alimentos. $\mathrm{El}$ acceso a los tornillos se cubrió con resina resilente fotopolimerizable, sobre ésta resina compuesta. La foto 7 muestra 3 entradas con resina resilente y las otras 3 ya con la resina compuesta, completando el procedimiento (Figuras 7A y 7B).

Como conclusión podemos observar que si evaluamos las características anatómicas del paciente (calidad y cantidad ósea, soporte labial, entre otras) vamos a obtener mejores resultados protésicos y estéticos.

\section{CORRESPONDENCIA:}

Roxana Escudero Loayza

Los Melones 220. La Molina

Teléfono: (51-1) 999106295

Correo electrónico: roxa_eslo@hotmail.com

\section{REFERENCIAS BIBLIOGRÁFICAS}

1. Eccellente T, Piombino M, Piattelli A, D'Alimonte E, Perrotti V, Iezzi G. Immediate loading of dental implants in the edentulous maxilla. Quintessence Int. 2011; 42 (4):281-289.

2. Gallucci G, Mavropoulos A, Bernard J, Belser U. Influence of immediate implant loading on peri-implant soft tissue morphology in the edentulous maxilla. Int $\mathrm{J}$ Oral Maxillofac Implants. 2007; 22(4):595-602.

3. Aglietta M, Siciliano V, Zwahlen M, et al. A systematic review of the survival and complication rates of implant supported fixed dental prostheses with cantilever extensions after an observation period of at least 5 years. Clin Oral Impl Res. 2009; 20(5):441-451.

4. Jaffin R, Kumar A, Berman C. Immediate loading of dental implants in the completely edentulous maxilla: A clinical report. Oral Maxillofac Implants. 2004; 19:721-730.

5. Jivraj S, Chee W, Corrado P. Treatment planning of the edentulous maxilla. British Dental Journal. 2006, 201(5):261-279.

6. Nikolopoulou F, Agapitou P. Rationale for choices of occlusal schemes for complete dentures supported by implants. Journal of Oral Implantology. 2006; 32 (4):200-203.

7. Parker M. The significance of occlusion in restorative dentistry. Dent Clin North Am. 1993; 37:341-351.

8. Bocklage R. Biomechanical aspects of monoblock implant bridges for the edentulous maxilla and mandible: concepts of occlusion and articulation. Implant Dent. 2004;13(1):49-52.

9. Cagna DR, Massad JJ, Daher T. Use of a powered toothbrush for hygiene of edentulous implant-supported prostheses. Compend Contin Dent Educ. 2011; 32(4): 84-88.

Recibido : 07/10/2013

Aceptado: 04/12/2013 